\title{
MÔ HİNH LIÊN DOANH ĐIỂN HİNH TRONG HOẠT ĐỘNG LỌC DẦU - BÀI HỌC KINH NGHIỆM TỪ NHÀ MÁY LỌC DẦU BAYERNOIL
}

\author{
Hoàng Thị Đào, Trương Như Tùng, Đào Minh Phượng \\ Viện Dầu khí Việt Nam \\ Email:daoht@vpi.pvn.vn \\ https://doi.org/10.47800/PVJ.2021.08-05
}

\section{Tóm tắt}

Liên doanh là hình thức hợp tác kinh tế có thể khai thác lợi thế, kinh nghiệm và nguồn lực của đối tác. Để tối ưu hiệu quả của mô hình liên doanh, việc đàm phán, thiết lập các điều khoản và cơ chế quản lý liên doanh cần được cân nhắc kỹ lưỡng ngay từ đầu, nếu không làm tốt có thể gây ra thiệt hại cho doanh nghiệp sau khi dự án được triển khai.

Bài viết giới thiệu các hình thức liên doanh phổ biến áp dụng trong lĩnh vực lọc dầu và mô hình điển hình được công ty dầu khí quốc tế áp dụng, đó là mô hình liên doanh của Nhà máy Lọc dầu Bayernoil. Mô hình này có thể áp dụng để quản lý hoạt động lọc dầu cũng như các dự án liên doanh khác có vốn đầu tư lớn ở Việt Nam.

Từ khóa: Mô hình liên doanh, Nhà máy Lọc dầu Bayernoil, Công ty TNHH Lọc hóa dầu Nghi Sơn (NSRP).

\section{Giới thiệu}

Hoạt động lọc dầu đòi hỏi vốn đầu tư lớn, công nghệ cao và phức tạp, yêu cầu quản lý vận hành nghiêm ngặt và nhân sự trình độ cao. Đứng trước rào cản về tỷ lệ sở hữu của doanh nghiệp nước ngoài tham gia vào hoạt động lọc dầu và phân phối sản phẩm dầu khí ở nước sở tại, hình thức liên doanh (joint ventures) đã được các công ty dầu khí sử dụng làm công cụ để thực hiện chiến lược gia nhập và phát triển thị trường mới. Đến nay, mục tiêu liên doanh trong lĩnh vực này đã có nhiều thay đổi, tận dụng các điểm mạnh, vị thế cạnh tranh của đối tác như: thương hiệu uy tín, trữ lượng dầu khí dồi dào, địa điểm sản xuất thuận lợi, năng lực tổ chức hiệu quả, công nghệ tiên tiến. Với các công ty dầu khí nhà nước, ngoài mục tiêu tăng quy mô, bổ sung nguồn vốn và chia sẻ rủi ro thì hợp tác còn với mong muốn thúc đẩy chuyển giao công nghệ và xây dựng năng lực chuyên môn và quản lý từ các công ty dầu khí quốc tế [1].

Các hình thức liên doanh cơ bản trong hoạt động lọc dầu [2], thể hiện rõ các mục tiêu và phạm vi liên doanh phù hợp với chiến lược tổng thể của các bên tham gia liên doanh (Bảng 1).

Ngày nhận bài: 15/7/2021. Ngày phản biện đánh giá và sửa chữa: 15 - 28/7/2021. Ngày bài báo được duyệt đăng: 12/8/2021.
Cho đến nay, hình thức liên doanh được các công ty dầu khí quốc tế áp dụng phổ biến, đặc biệt đối với các nhà máy lọc dầu ở châu Âu, là mô hình liên doanh đối tác chiến lược sản xuất. Các nhà máy lọc dầu quản lý vận hành theo hình thức liên doanh sản xuất như:

- Liên doanh Nhà máy Lọc dầu Bayernoil Raffineriegesellschaft mbH (Bayernoil) tại Cộng hòa Liên bang Đức, liên doanh giữa các bên gồm Eni (20\%), Varo Energy (51,43\%) và Rosneft (28,57\%). Công suất 10,3 triệu tấn dầu thô/năm. Các sản phẩm chính là $\mathrm{LPG}$, xăng RON95/98, diesel, Jet A-1/Kerosene, Heating Oil (solid fuel), bitumen và polypropylene $[3,4]$.

- Liên doanh Nhà máy Lọc dầu PCK Raffinerie GmbH tại Cộng hòa Liên bang Đức, các đối tác gồm: Rosneft $(54,17 \%)$, Eni $(8,33 \%)$ và Royal Dutch Shell $(37,5 \%)$, dự kiến thương vụ Royal Dutch Shell bán toàn bộ cổ phần cho Alcmene GmbH (thuộc Liwathon Group) hoàn thành trong nửa cuối năm 2021 [5]. Công suất 11,6 triệu tấn dầu thô/năm. Các sản phẩm chính là xăng, diesel, FO, LPG, bitum, kerosene, lưu huỳnh, aromatics (benzene, toluene, xylene). PCK là một trong những nhà máy lọc dầu đầu tiên ở Đức sử dụng nhiên liệu sinh học và là nhà sản xuất các thành phần nhiên liệu sinh học chất lượng cao $[3,4]$.

- Liên doanh Nhà máy Lọc dầu MiRO tại Cộng hòa 
Bảng 1. Các hình thức liên doanh cơ bản trong hoạt động lọc dâu

\begin{tabular}{|c|c|}
\hline Hình thức liên doanh & Phạm vi liên doanh \\
\hline Đối tác chiến lược & 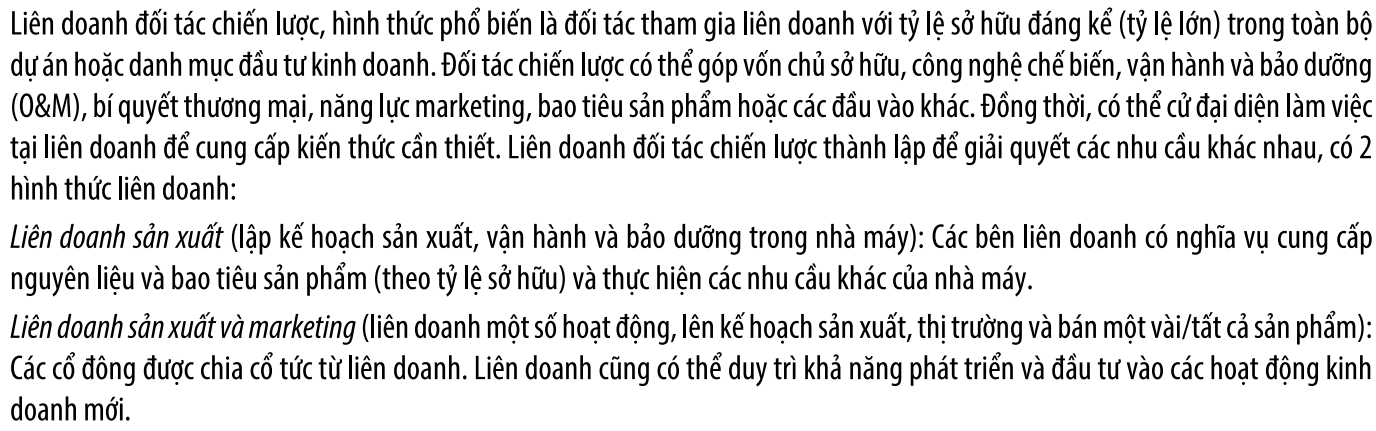 \\
\hline Đối tác sản phẩm & 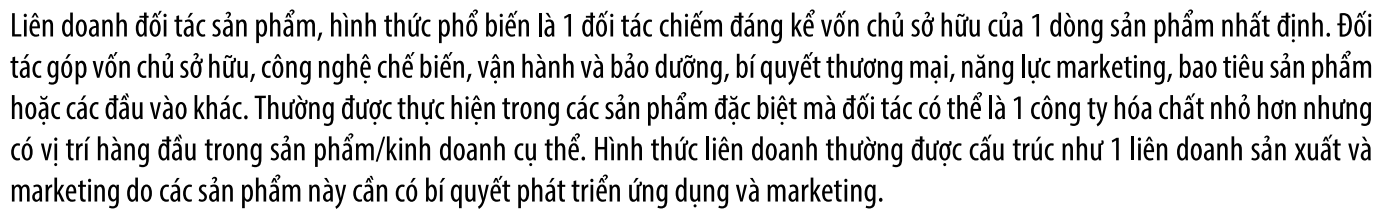 \\
\hline Liên doanh dịch vụ & $\begin{array}{l}\text { Hình thức liên doanh dịch vư phổ biến là đối tác tham gia liên doanh để phát triển các tài sản thứ cấp như cơ sở hạ tẩng, tiên ích, } \\
\text { hậu cẩn (ví dụ: trạm xăng dầu) mà các cổ đông chính không muốn thực hiện; thông qua liên doanh, đối tác có quyển kiểm soát } \\
\text { hoạt động và quản lý các tài sản đó. }\end{array}$ \\
\hline Đối tác công nghệ & $\begin{array}{l}\text { Trong hình thức liên doanh đối tác công nghê sẽ có } 1 \text { đối tác tham gia là công ty công nghể bản quyền (được cấp phép) tham gia } \\
\text { liên doanh để cung cấp quy trình công nghệ và hỗ trợ kỹ thuật vận hành liên tục, có thể trong một dự án đơn lẻ hoặc cho toàn } \\
\text { hoạt động kinh doanh (có nhiểu nhà máy/tài sản). }\end{array}$ \\
\hline
\end{tabular}

Liên bang Đức là liên doanh giữa Rosneft (24\%), Royal Dutch Shell (32,25\%), ExxonMobil (25\%) và Phillips 66 $(18,75 \%)$. Công suất 14,9 triệu tấn/năm. Các sản phẩm gồm LPG, xăng RON95/95, diesel, FO... [3].

Để hiểu các nguyên tắc và cách thức điều hành một liên doanh theo hình thức liên doanh đối tác chiến lược sản xuất, nhóm tác giả phân tích thực tế vận hành liên doanh Nhà máy Lọc dầu Bayernoil.

\section{Mô hình liên doanh Nhà máy Lọc dầu Bayernoil}

Quan hệ liên doanh giữa các bên liên doanh (cổ đông) được quy định rõ trong Thỏa thuận liên minh (Consortium Agreement) ký kết giữa các bên liên doanh trên nguyên tắc [6]:

- Cùng làm lợi cho Nhà máy Lọc dầu Bayernoil nhằm tối ưu công suất vận hành và hiệu quả kinh tế, các bên cam kết áp dụng các kiến thức mới nhất về sản xuất/công nghệ và quản lý vào Nhà máy.

- Vai trò của các bên liên doanh như nhau, không sử dụng quyền sở hữu làm phương hại đến bất kỳ bên liên doanh khác. Các bên liên doanh có quyền nhận tất cả thông tin từ nhà máy lọc dầu. Ứng xử của Nhà máy Lọc dầu Bayernoil đối với các bên liên doanh là như nhau, không phụ thuộc vào tỷ lệ sở hữu cao hay thấp.
- Các bên liên doanh cung cấp nguyên liệu và tiêu thụ sản phẩm theo tỷ lệ sở hữu trong Nhà máy Lọc dầu Bayernoil dựa trên các quy định đã thống nhất giữa các bên liên doanh và Nhà máy để đảm bảo Nhà máy vận hành an toàn, ổn định và hiệu quả (cung cấp dầu thô kịp thời, loại dầu trong mức quy định, lưu kho sản phẩm trong phạm vi cho phép...).

- Các bên liên doanh tự quản lý chuỗi giá trị tại Nhà máy Lọc dầu Bayernoil tương ứng với phần vốn góp, từ việc cung ứng dầu thô (quyền quyết định mua, loại dầu...), cơ cấu sản phẩm sản xuất và bán sản phẩm ra thị trường.

- Các quyết định trong Nhà máy Lọc dầu Bayernoil chỉ được thông qua khi 100\% cổ đông đồng ý. Trường hợp nếu quyết định có lợi cho 1 cổ đông mà không có hại cho các cổ đông khác thì được chấp nhận (các cổ đông khác không được ngăn cản trường hợp này).

Ví dụ: Nhà máy Lọc dầu Bayernoil chỉ có thể sản xuất dầu thô có hàm lượng lưu huỳnh tối đa là $0,14 \%$, các cổ đông có thể cung cấp loại dầu trên/dưới mức đó nếu hàm lượng lưu huỳnh trung bình đáp ứng mức quy định. Khi đó, cho phép 1 bên có thể cung cấp loại dầu có hàm lượng lưu huỳnh trên mức $0,14 \%$, tuy nhiên sẽ chịu rủi ro nếu như hàm lượng lưu huỳnh trung bình không đáp ứng mức tối đa cho phép thì Nhà máy lọc dầu sẽ từ chối nhận. 
- Các bên thành lập các ủy ban giám sát hoạt động của Nhà máy Lọc dầu Bayernoil theo thỏa thuận liên doanh nhưng không hạn chế tính độc lập của Ban quản lý điều hành Nhà máy.

- Các bên liên doanh và Nhà máy Lọc dầu Bayernoil sử dụng kỹ thuật Linear Programming (LP) để lập kế hoạch và tính toán hiệu quả vận hành, sử dụng chung 1 bộ giá.

- Trách nhiệm của Nhà máy Lọc dầu Bayernoil đối với các bên liên doanh:

+ Nhà máy Lọc dầu Bayernoil hoạt động như trung tâm gia công phi lợi nhuận (non-profit center), có trách nhiệm vận hành an toàn và tối ưu trên cơ sở các loại dầu thô do các bên liên doanh cung cấp. Nhà máy sử dụng LP để tính toán hiệu quả vận hành tối ưu trên cơ sở các loại dầu thô do các bên cung cấp. Các bên liên doanh cũng sử dụng LP tính toán hiệu quả đối với loại dầu của mình cung cấp cho nhà máy (cơ cấu sản phẩm tối thiểu bên liên doanh nhận được tương ứng với dầu thô cung cấp). Đối với các loại dầu thô do các bên liên doanh cung cấp, Nhà máy sẽ trộn các loại dầu thô để sản xuất sao cho cơ cấu sản phẩm tối ưu hơn là sử dụng từng loại dầu thô riêng biệt. Trong trường hợp sản lượng sản xuất của Nhà máy cao hơn kế hoạch thì sản lượng dư (cao hơn) được chia cho các bên liên doanh theo tỷ lệ sở hữu.

+ Nhà máy Lọc dầu Bayernoil có trách nhiệm xây dựng chiến lược (10 năm), kế hoạch (5 năm), kế hoạch ngân sách hàng năm, kế hoạch vận hành tháng theo chỉ dẫn trong Thỏa thuận liên doanh.

+ Giám đốc nhà máy có trách nhiệm báo cáo KPIs cho các bên liên doanh. Kết quả hoạt động của Nhà máy được tính trên một bộ giá (được thiết lập từ trước, không theo giá thị trường).

+ Kiểm toán thực hiện định kỳ 2 năm, 3 năm và 5 năm tùy hạng mục kiểm toán (riêng với Jet $A 1$ thực hiện kiểm toán 1 lần/năm).

Tổ chức quản lý Nhà máy Lọc dầu Bayernoil [4], bộ máy tổ chức của nhà máy gồm Đại hội đồng cổ đông, Hội đồng liên minh, Ban kiểm soát, Ban điều hành và các ủy ban (Hình 1), chức năng nhiệm vụ được quy định trong Thỏa thuận cổ đông (Shareholders Agreement). Nhà máy được ủy quyền quyết định các vấn đề như: chủ động mua sắm theo kế hoạch được phê duyệt; Giám đốc Nhà máy được ủy quyền quyết định đầu tư mức từ 2 - 3 triệu EURO, tương đương khoảng 70 - 100 tỷ đồng; Ủy ban Điều hành (OpCo)/Project team, Ủy ban Kế hoạch sản xuất (PPC) được ủy quyền quyết định ở mức 0,5 triệu EURO, tương đương khoảng 17 tỷ đồng. Các cổ đông trực tiếp tham gia Nhóm dự án (Project Team) để giám sát và kịp thời ra các quyết định trong phạm vi được ủy quyền.

- Hội đồng liên minh (Consortium Committee) [6]: Theo Thỏa thuận liên minh: (1) nhân sự trong Hội đồng liên minh được các bên liên doanh cử từ 1 - 2 người theo

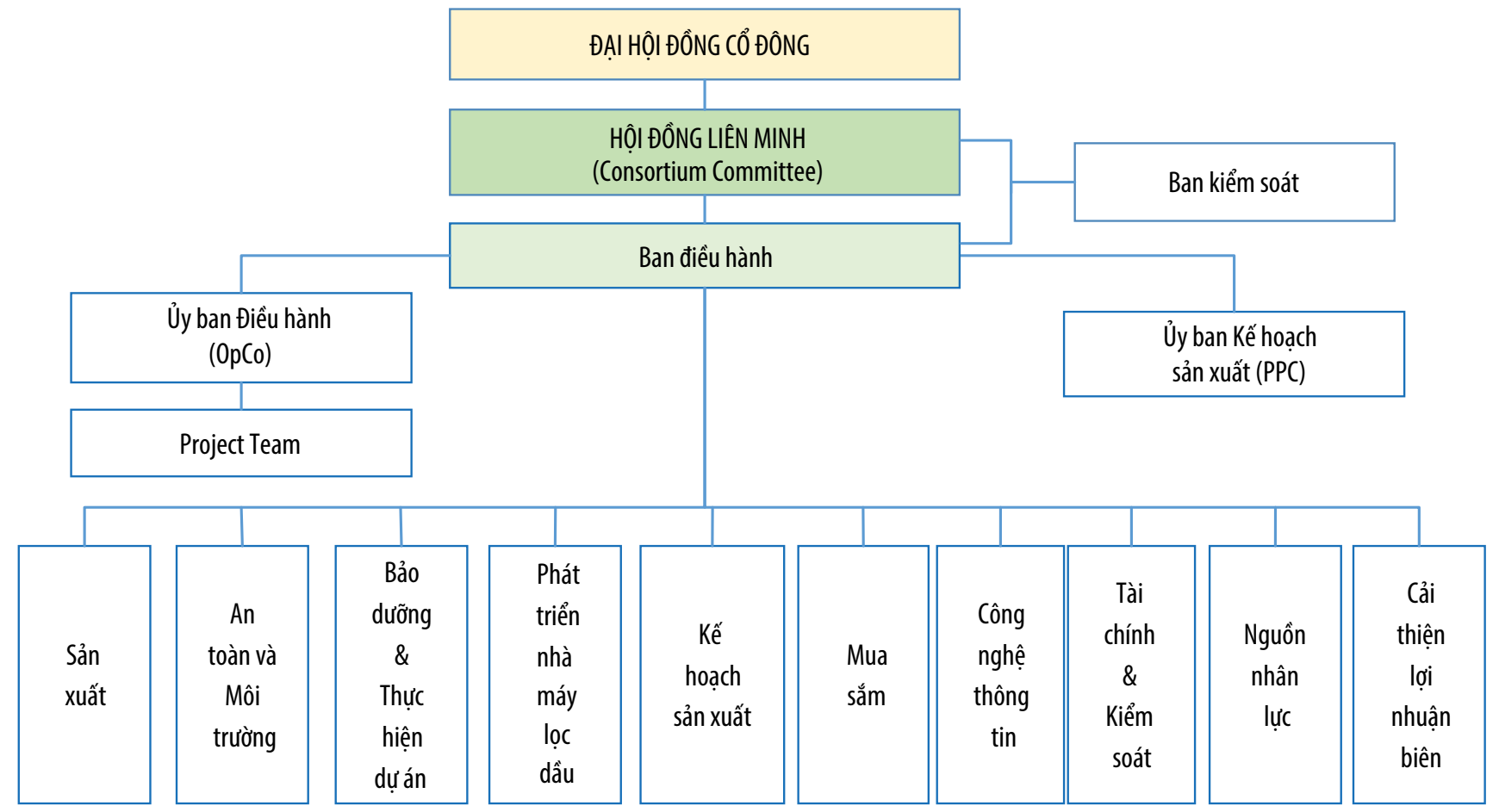

Hinh 1. Cơ cấu tổ chức quản lý Nhà máy Lọc dầu Beyernoil. 
tỷ lệ góp vốn. Chủ tịch Hội đồng liên minh luân phiên thay đổi 2 năm/lần cho các bên lần lượt bởi Eni, OMV, Ruhr Oel, OMV và $B P$ bắt đầu từ ngày 1/1/2004; (2) Phó Chủ tịch Hội đồng liên minh do bên được đề cử làm Chủ tịch của nhiệm kỳ tiếp theo đảm nhiệm; (3) Hội đồng liên minh có trách nhiệm xây dựng các quy tắc thủ tục (rules of procedure), thành lập các ủy ban, ban hành các hướng dẫn (guidelines) và các chỉ dẫn (instructions) cho Ban điều hành và giám sát Ban điều hành.

Các quyết định phải được Hội đồng liên minh thông qua gồm:

+ Các vấn đề liên quan đến Nhà máy Lọc dầu Bayernoil theo quy định trong Thỏa thuận cổ đông;

+ Các Nghị quyết của Ban kiểm soát và Đại hội đồng cổ đông;

+ Các vấn đề liên quan được đưa ra trong Thỏa thuận liên minh, cũng như các vấn đề được vận dụng từ Thỏa thuận liên minh trong mối quan hệ của các bên liên doanh và Nhà máy;

+ Các vấn đề mà Ban điều hành không đạt được thống nhất, Hội đồng liên minh sẽ quyết định;

+ Các vấn đề cần sự đồng thuận của các bên liên doanh (100\% số phiếu), gồm: ngân sách chế biến; các khoản vay từ các cổ đông, nhận và cấp các khoản vay vượt quá phạm vi hoạt động kinh doanh thông thường, đặc biệt các khoản nợ và khoản vay dài hạn cũng như các khoản bảo lãnh và bảo đảm bởi Nhà máy Lọc dầu Bayernoil; các nguyên tắc về quyền chế biến hoặc trách nhiệm chế biến của các bên liên doanh; kho chứa và kế hoạch sản xuất; đầu tư, xây dựng, dừng hoạt động, dỡ bỏ một phần hoặc toàn bộ Nhà máy Lọc dầu Bayernoil; các quy định chi tiết về tài chính đầu tư; các cơ sở và hướng dẫn kế toán, phân bổ chi phí, chi phí chế biến, sản lượng, báo cáo...; xác định lợi nhuận và phân phối lợi nhuận; mở rộng hoạt động kinh doanh; các thỏa thuận chế biến giữa Nhà máy Lọc dầu Bayernoil và bên thứ 3; sử dụng công cụ tài chính phái sinh...

+ Các nghị quyết khác của Hội đồng liên minh được thông qua với đa số phiếu bầu (75\% số phiếu).

- Ban điều hành Nhà máy Lọc dầu Bayernoil $[4,6]$ gồm: 2 giám đốc, 1 giám đốc phụ trách công nghệ và 1 giám đốc phụ trách điều hành (mô hình 2 giám đốc có tính yếu tố lịch sử, các nhà máy khác chỉ có 1 giám đốc); nguyên tắc ra quyết định là đồng thuận, trường hợp 2 giám đốc không thống nhất sẽ đưa lên Hội đồng liên minh. Giám đốc Nhà máy Lọc dầu Bayernoil do bên liên doanh có sở hữu nhiều nhất đề cử và tất cả các cổ đông tham gia phỏng vấn. Các vị trí khác trong Nhà máy do Giám đốc bổ nhiệm.

- Ủy ban Điều hành (Operation Committee) [4]: Ủy ban Điều hành họp 3 tháng/lần, điều hành cuộc họp là Giám đốc Nhà máy Lọc dầu Bayernoil, bàn về chiến lược và ngân sách, cụ thể: thông qua Biên bản họp kỳ trước; danh sách các hành động kỳ này; báo cáo KPIs đạt được (sử dụng để trả lương thưởng cho Ủy ban Điều hành); ngân sách năm nay và dự kiến năm sau về phụ trợ, nhân công, bảo dướng, cơ sở hạ tầng...; các dự án; chuẩn bị cho Kế hoạch 5 năm về ngân sách đại tu (turnaround); các mục tiêu về thương hiệu, tài chính/đầu tư, quy trình hoạt động, con người, đào tạo, sáng kiến; về các dự án (tình hình thực hiện, quyết định triển khai tiếp hay dừng; cân bằng tổng thể tài sản; các báo cáo của Ban điều hành, Ban kế hoạch sản xuất, Ban kiểm định chất lượng và Kiểm toán.

- Ủy ban Kế hoạch sản xuất (PPC) [4] xây dựng kế hoạch hàng tháng và quản lý hoạt động hàng ngày các vấn đề kinh tế - kỹ thuật và tối ưu hiệu quả vận hành. Ủy ban Kế hoạch sản xuất họp hàng tuần với Ủy ban Điều hành, điều hành cuộc họp bởi Trưởng bộ phận Kế hoạch sản xuất (điều độ sản xuất), bàn về kế hoạch sản xuất tháng, cụ thể: tình trạng hoạt động của Nhà máy; các vấn đề chính, thách thức vận hành, đưa ra các ưu tiên, xử lý xung đột giữa các cổ đông và Nhà máy; xác định và giám sát các chỉ số/hành động đã thống nhất giữa các cổ đông và Nhà máy trên cơ sở đề xuất (tính toán dựa trên mô hình LP, thông số kỹ thuật, chế độ vận hành thực tế).

- Nhóm dự án (Project Team) [6] hỗ trợ cho Ủy ban Điều hành, họp hàng tháng với các cổ đông và báo cáo trực tiếp cho Ủy ban Điều hành, chủ trì cuộc họp là Trưởng bộ phận Kỹ thuật, bàn về: sử dụng ngân sách dự án; thực tế triển khai dự án; các vấn đề cần giải quyết/phát sinh; các chỉ số KPI dự án như chi phí vốn, tiến độ, kết quả; các dự án thành phần, thiết bị thay thế...

Với tỷ lệ góp vốn của mình, Eni được cử 1 đại diện trong Hội đồng liên minh, 1 đại diện trong Ban Kế hoạch sản xuất và 1 đại diện trong Ban điều hành.

\section{3. Điểm khác biệt cơ bản giữa mô hình liên doanh Nhà máy Lọc dầu Bayernoil và Liên hợp Lọc hóa dầu Nghi Sơn}

Công ty TNHH Lọc hóa dầu Nghi Sơn (NSRP) thuộc nhóm liên doanh đối tác chiến lược sản xuất - marketing, được tổ chức vận hành theo mô hình công ty trách nhiệm hữu hạn 2 thành viên trở lên. Các bên liên doanh gồm 4 
đối tác trong đó Tập đoàn Dầu khí Việt Nam (PVN) có 25,1\% vốn góp, còn lại $74,9 \%$ do các cổ đông nước ngoài gồm: Idemitsu Kosan Co., Ltd. (IKC, 35,1\%); Kuwait Petroleum Europe B.V. (KPE, 35,1\%) và Mitsui Chemical, Inc. (MCI, $4,7 \%)$. Với tỷ lệ góp vốn của PVN, theo pháp luật hiện hành của Việt Nam và quy định tại Hợp đồng liên doanh thì quyền tham gia vào điều hành hoạt động sản xuất kinh doanh ở NSRP của PVN rất hạn chế [7]. Cụ thể:

- Các vấn đề phải có sự đồng thuận 100\% tổng số vốn góp của thành viên dự họp: (1) chỉ định nhà thầu FEED, (2) lựa chọn nhà thầu EPC và PMC, (3) phê duyệt điều kiện và điều khoản của Hợp đồng vay vốn, (4) sửa đổi và bổ sung vốn điều lệ, (5) tổ chức lại hoặc giải thể doanh nghiệp. Các vấn đề khác chỉ cần $65 \%$ tỷ lệ biểu quyết. Do đó, với tỷ lệ vốn góp của PVN là 25,1\%, PVN không đủ tỷ lệ biểu quyết để phủ quyết các vấn đề quan trọng khác như các gói thầu mua sắm lớn. Quy định này không trái với Luật Doanh nghiệp nhưng có ảnh hưởng lớn đến khả năng kiểm soát của PVN đối với hoạt động của NSRP. Điều này khác biệt rất nhiều so với mô hình liên doanh của Nhà máy Lọc dầu Bayernoil, mọi quyết định chỉ được thông qua khi $100 \%$ cổ đông đồng ý.

- Ràng buộc các bên về cung ứng và phân phối sản phẩm: (1) KPE cung cấp dầu thô dài hạn (70 năm); (2) Idemitsu Kosan có trách nhiệm hỗ trợ kỹ thuật; (3) Mitsui Chemical có trách nhiệm bao tiêu sản phẩm PP và (3) PVN có trách nhiệm bao tiêu sản phẩm lọc dầu. Đây là nội dung rất khác biệt với hình thức liên doanh tại Nhà máy Lọc dầu Bayernoil, các bên liên doanh quản lý chuỗi cung ứng theo tỷ lệ góp vốn tại nhà máy lọc dầu, từ cung ứng dầu thô, quyết định cơ cấu sản phẩm sản xuất và phân phối sản phẩm.

- Nhân sự theo thỏa thuận hợp đồng liên doanh: Các bên góp vốn có 1 đại diện trong Hội đồng thành viên $(1 \mathrm{KC}, 1 \mathrm{PVN}, 1 \mathrm{KPE}$ và $1 \mathrm{MCl})$; trong Ban Tổng giám đốc có 3 đại diện (1 IKC, 1 KPE và 1 PVN). Trong đó, vị trí Tổng giám đốc và Chủ tịch HĐTV sẽ do KPE và IKC luân phiên đảm nhiệm. Việc quản lý điều hành Liên hợp Lọc hóa dầu Nghi Sơn do các bên liên doanh trực tiếp cử người tham gia điều hành hoạt động sản xuất và phân chia lợi nhuận/ rủi ro/thua lỗ trên cơ sở lợi ích tương ứng với tỷ lệ góp vốn. Mô hình vận hành này khác biệt hoàn toàn với Nhà máy Lọc dầu Bayernoil, được vận hành như một thực thể độc lập theo hình thức phi lợi nhuận, tỷ lệ chia sẻ công suất tương đương với quyền sở hữu của mỗi bên và trả phí chế biến cho Nhà máy. Nhà máy Lọc dầu Bayernoil được giao toàn quyền điều hành, quyết định sản xuất tối ưu và các bên liên doanh kiểm soát hoạt động của Nhà máy dựa trên các KPIs.
- Quản lý của Công ty mẹ PVN đối với người đại diện tại NSRP: Phân cấp ủy quyền cho người đại diện vốn góp của PVN tại NSRP còn hạn chế (được quyết định đến 20 tỷ đồng), quá thấp so với thông lệ và đối tác nước ngoài cùng điều hành liên doanh, được phân cấp ủy quyền quyết mọi vấn đề liên quan. Do phân cấp ủy quyền thấp nên người đại diện của PVN cần xin phê duyệt của Công ty mẹ PVN trước khi biểu quyết, dẫn đến quá trình ra quyết định bị chậm.

\section{Kết luận và khuyến nghị}

Mỗi mô hình liên doanh lọc dầu có lợi thế nhất định, phụ thuộc vào bối cảnh và mục tiêu của các bên liên doanh tại thời điểm ký kết. Với mô hình liên doanh của Nhà máy Lọc dầu Nghi Sơn, nguồn dầu thô cung ứng và việc phân phối sản phẩm được các bên bảo đảm thực hiện trong dài hạn. Mô hình liên doanh lọc dầu của các công ty dầu khí quốc tế cho phép các bên liên doanh quyền chủ động quản lý và giám sát được toàn chuỗi giá trị từ cung ứng dầu thô đầu vào, quyết định cơ cấu sản phẩm và phân phối sản phẩm theo tỷ lệ góp vốn.

Theo đánh giá của các chuyên gia, Nhà máy Lọc dầu Bayernoil được đánh giá thuộc nhóm có hoạt động liên doanh tốt (top JV performance). Cách thức tổ chức quản lý và vận hành, các nguyên tắc và mối quan hệ đối tác trong liên doanh Nhà máy Lọc dầu Bayernoil là kinh nghiệm hữu ích cho PVN tham khảo và vận dụng, không chỉ trong lính vực lọc dầu. Dưới đây là một số khuyến nghị về công tác quản lý các nhà máy lọc dầu của PVN:

- Hướng tới quản lý nhà máy như một thực thể độc lập (công ty/chi nhánh) để tăng vai trò của nhà máy (Giám đốc nhà máy) chịu trách nhiệm hoàn toàn về hoạt động chế biến, đảm bảo tối ưu cơ cấu sản phẩm và đảm bảo vận hành an toàn. Giám đốc nhà máy được giao quyền quản lý các phòng ban trong nhà máy, tuyển dụng, đánh giá nhân sự..., phát huy sức mạnh của các bộ phận điều độ sản xuất và bộ phận kỹ thuật.

- Yêu cầu sử dụng kỹ thuật LP để đánh giá hiệu quả kinh tế và quản lý nhà máy thống nhất từ Công ty mẹ PVN, doanh nghiệp quản lý nhà máy và tại các nhà máy lọc dầu.

- Xây dựng cơ chế kiểm tra, giám sát hiệu quả thông qua chỉ số hoạt động chính (KPIs), ví dụ: hiệu suất vận hành, năng lượng sử dụng, tiêu hao vật tư, bảo trì, nhân sự, chi phí, lợi nhuận biên...

- Về quản lý lợi nhuận biên lọc dầu (refining margin): Tối ưu hiệu quả sản xuất và vận hành thông qua các sáng 
kiến vận hành; đặt mục tiêu tối ưu năng lượng (cho 5 năm và có kế hoạch thực hiện cụ thể cho từng năm); đa dạng nguồn cung cấp nguyên liệu đầu vào với chi phí cạnh tranh.

- Cử đại diện của Công ty mẹ - PVN có kinh nghiệm và được trao quyền tối đa để trực tiếp tham gia vào hoạt động hàng ngày và kiểm soát hoạt động của các nhà máy. Đồng thời, PVN xây dựng cơ chế kiểm tra, giám sát phù hợp nhằm tăng tính chủ động, trách nhiệm cho người đại diện.

- Xây dựng hướng dẫn quản lý đối tác, đặc biệt đối với các liên doanh/liên kết, đối tác chiến lược nước ngoài; áp dụng mô hình liên doanh theo thông lệ tốt trên nguyên tắc hai bên cùng có lợi nhằm tối đa lợi ích tổng thể; các bên có trách nhiệm áp dụng các kiến thức quản lý - kỹ thuật tốt nhất cho nhà máy; có quyền bình đẳng trong việc ra quyết định và nhận mọi thông tin từ nhà máy.

\section{Tài liệu tham khảo}

[1] Justin Pettit and Mark Jelinek, "The joint venture (JV) handbook", IHS Consulting, 2012. [Online]. Available: https://ihsmarkit.com/pdf/The-IHS-Consulting-JVHandbook_165622110913044932.pdf.

[2] Wood Mackenzie, "Downstream organisational learnings", 2019.

[3] Rosneft, "Rosneft in Germany". [Online]. Available: https://www.rosneft.de/rosneft-germany/?lang=en.
[4] Truong Nhu Tung, "Refinery economics course for VPI", 2014.

[5] Royal Dutch Shell, "Shell sells its minority shareholding in PCK Schwedt joint venture refinery to Alcmene", 8/7/2021. [Online]. Available: https://www.shell. com/media/news-and-media-releases/2021/shell-sellsits-minority-shareholding-in-pck-schwedt-joint-venturerefinery-to-alcmene.html.

[6] Eni Deutschland GmbH, BP Europa SE, OMV Deutschland $\mathrm{GmbH}$ and Ruhr Oel $\mathrm{GmbH}$, "Consortium agreement 2003 on the joint venture Bayernoil Raffineriegesellschaft $m b H^{\prime \prime}, 2011$.

[7] Hoàng Thị Đào và nnk, "Đánh giá và hoàn thiện mô hình quản trị doanh nghiệp cho các đơn vị sản xuất kinh doanh khâu sau của Tập đoàn Dâu khí Quốc gia Việt Nam", Viện Dầu khí Việt Nam, 2021.

[8] Hoàng Thị Đào và nnk, "Nghiên cứu mô hình tổ chức quản lý sản xuất kinh doanh đối với Nhà máy lọc dâu tại Đức của Công ty ENI", Viện Dầu khí Việt Nam, 2020.

[9] Hoàng Thị Đào, Hoàng Thị Phượng, và Lương Thu Hà, “Mô hình tổ chức quản lý hoạt động hạ nguồn của các công ty dầu khí quốc gia trong khu vực Đông Nam Á và kinh nghiệm cho Tập đoàn Dầu khí Việt Nam", Tạp chí Dâu khí, Số 5, trang 51 - 59, 2020.

\title{
JOINT VENTURE MODEL IN OIL REFINERY - LESSONS LEARNED FROM BAYERNOIL REFINERY
}

\author{
Hoang Thi Dao, Truong Nhu Tung, Dao Minh Phuong \\ Vietnam Petroleum Institute \\ Email: daoht@vpi.pvn.vn
}

\section{Summary}

Joint venture is a form of economic co-operation that can exploit the advantages, experiences and resources of the partners. To optimise the effectiveness of joint venture models, the negotiation and establishment of the terms of agreement and the management mechanism of joint ventures should be carefully considered from the beginning, otherwise, it may cause harm to the business after the project is implemented.

The article introduces the common joint venture models in the oil refinery sector and a typical joint venture model applied by an international oil and gas company, the Bayernoil refinery joint venture. This model can be applied to manage oil refining activities as well as other joint venture projects with large investments in Vietnam.

Key words: Joint venture model, Bayernoil Refinery, Nghi Son Refinery and Petrochemical LLC (NSRP). 